\title{
EL NACIMIENTO DEL NEOBARROCO EN LA POLÉMICA ENTRE MUNDO NUEVO Y CASA DE LAS AMÉRICAS
}

\author{
THE BEGINNING OF NEOBAROQUE IN THE CONTROVERSY BETWEEN \\ MUNDO NUEVO AND CASA DE LAS AMÉRICAS
}

\author{
León Felipe Barrón Rosas \\ Universidad Nacional Autónoma de México. México \\ leon_felipe9@yahoo.com.mx
}

\begin{abstract}
Resumen: El ámbito cultural e intelectual de la década de los sesenta constaba de diversos espacios e instituciones que se extendían como redes de interacción discursiva; desde revistas como Casa de las Américas y Mundo Nuevo se fueron fijando posturas relativas a la labor de los escritores frente a la coyuntura especial que había creado la Revolución cubana, al mismo tiempo que surgieron perspectivas para pensar lo latinoamericano. En este contexto de discusión política e ideológica álgida, Severo Sarduy configuró su propuesta neobarroca, específicamente, en los artículos que publicó en la revista Mundo Nuevo; sin embargo, los estudios centrados en su obra dejan de lado ese hecho. En este trabajo se estudian algunos de estos textos que pueden ser considerados el inicio del neobarroco, a la luz de su contexto social y las polémicas intelectuales de ese momento.
\end{abstract}

Palabras clave: Severo Sarduy, Neobarroco, Mundo Nuevo, Casa de las Américas.

\begin{abstract}
The sixties' cultural and intellectual field consisted of several spaces and institutions that spread as discursive interaction nets. From journals like Casa de las Américas and Mundo Nuevo, different ways of thinking the writers' labor in the face of the special context created by the Cuban Revolution were stablished, at the same time that perspectives to think the Latin-American emerged. In this context of culminating political and ideological discussion, Severo Sarduy's Neobaroque proposal took shape, specifically, in his articles published in Mundo Nuevo journal. Nevertheless, most of the analysis focused on his work do not address that fact. In this work some of these articles, that can be considered the beginning of Neobaroque, are studied in the light of their social context and the intellectual controversies of the time.
\end{abstract}

Keywords: Severo Sarduy, Neobaroque, Mundo Nuevo, Casa de las Américas.

Recibido: 26/11/2018. Aceptado: 14/04/19. 


\section{Introducción}

Qevero Sarduy publicó su ensayo "El barroco y el neobarroco" en 1972 en el libro América Latina en su literatura, coordinado por César Fernández Moreno. La inclusión del ensayo de Sarduy en esta antología ${ }^{1}$ es bastante significativa, puesto que esta publicación fue la suma o recuento de las diversas posturas críticas en torno a la literatura latinoamericana derivadas de la convulsa década del sesenta. ${ }^{2}$ Estos años estuvieron llenos de polémicas generadas alrededor de lo social, lo político y lo literario; en varias de ellas, dos nombres estaban siempre presentes: Emir Rodríguez Monegal y Ángel Rama. Para la configuración del campo intelectual, especialmente de los sesenta, fueron por demás importantes sus voces, así como el posicionamiento estratégico de publicaciones en las que participaron como Casa de las Américas y que incluso llegaron a dirigir: la sección literaria del semanario Marcha y la revista Mundo Nuevo. En torno a las tensiones entre las directivas de estas publicaciones se conformaron flancos, cada uno con la voluntad de legitimarse como el discurso válido para hablar sobre Latinoamérica. Quien terminó imponiéndose fue Casa de las Américas en conjunto con Marcha; Mundo Nuevo acabó por ser una publicación efímera con tan sólo dos años de existencia (1966-1968). En esta revista, Severo Sarduy fue dando a conocer los primeros atisbos del nacimiento del neobarroco.

La obra de Sarduy se acomodó en diferentes espacios ${ }^{3}$; sin embargo,

\footnotetext{
${ }^{1}$ Como apunta Ignacio Sánchez Prado, este libro: "Traza una serie de rutas que condensaron los resultados de lo que, en ese entonces, fueron los eventos más significativos en la construcción de un mapa literario-crítico regional: el llamado boom de la literatura latinoamericana y la comunidad intelectual generada en torno a la Revolución cubana, a punto de entrar en crisis en ese momento debido al caso Padilla. Esta antología incluyó a muchos de los que, en su momento, eran las figuras punteras en la construcción de una disciplina regional, alrededor principalmente de la búsqueda de un sistema teórico crítico que diera cuenta de las especificidades históricas, sociales y estéticas del corpus literario" (2006, p. 7).

${ }^{2}$ Caso curioso de esta antología es la ausencia muy notoria de Ángel Rama.

${ }^{3}$ Por la cantidad de colaboraciones en revistas, periódicos y suplementos culturales como Sur, Plural, Vuelta, Revista de la Universidad Nacional de México, Imagen, Diálogos, La Nación; y el origen de las editoriales que dieron acogida a su obra: Joaquín Mortiz, Sudamericana, Monte Âvila y Fondo de Cultura Económica, no cabe la posibilidad de señalar que la obra sarduyana se desarrolló fuera del campo intelectual latinoamericano y de sus preocupaciones, como a veces se ha señalado.
} 
sus textos nunca fueron acogidos por Casa de las Américas. La ausencia de Sarduy en la publicación dirigida por Roberto Fernández Retamar nos dice mucho del lugar que ocupó su obra y cómo fue tomada por la crítica que se volvería la hegemónica en ese momento. Donde sí tuvo lugar fue en la revista Mundo Nuevo, dirigida por Emir Rodríguez Monegal desde Francia. Los textos que Sarduy publicó aquí pertenecen a lo que podemos considerar como el segundo periodo de su obra, caracterizado por una vuelta al origenismo, especialmente a Lezama Lima, aspecto que le permitió iniciar una lectura neobarroca de la cultura latinoamericana, en la que combinó algunos conceptos teóricos del estructuralismo y el postestructuralismo. Si nos damos a la tarea de revisar los textos del nacido en Camagüey en esta publicación, veremos que ya estaba ensayando sus ideas posteriormente vertidas en 1972 en el libro coordinado por César Fernández Moreno. Podemos asegurar que Mundo Nuevo fue el espacio de gestación del neobarroco.

Como dice Beatriz Sarlo (1992, p. 12), la publicación de revistas es una forma de hacerle frente a nuestro tiempo. Hacer una revista es crear una manera de estar en nuestra contemporaneidad, de tomarla, de analizarla y de fijar una postura ante ella. La revista establece valores y vínculos discursivos en los que se dirimen problemáticas puntuales en momentos particulares. En este sentido es como entendemos Mundo Nuevo y la revista Casa de las Américas. En ellas se revelaron posiciones encontradas en torno a lo latinoamericano y la tarea del intelectual frente a los retos de pensarse respecto a su contemporaneidad. La gestación del neobarroco estuvo impregnada de este contexto y en relación directa con las polémicas entre estas dos revistas y su visión de lo latinoamericano.

\section{La disputa entre Ángel Rama y Emir Rodríguez Monegal}

Las siguientes palabras de Mario Vargas Llosa resumen la enemistad entre Ángel Rama y Emir Rodríguez Monegal, y dan un panorama conciso de cómo la animadversión que sentían el uno por el otro resultó fructífera en el ámbito de la crítica literaria:

Todo organizador de simposios, mesas redondas, congresos, conferen- 
cias y conspiraciones literarias, del Río Grande a Magallanes, sabía que conseguir la asistencia de Ángel Rama y de Emir Rodríguez Monegal era asegurar el éxito de la reunión: con ellos presentes habría calidad intelectual y pugilismo virtuoso. Ángel más sociólogo y político; Emir, más literario y académico; aquél más hacia la izquierda, éste más a la derecha, las diferencias entre ambos uruguayos fueron providenciales, el origen de los más estimulantes torneos intelectuales a los que me ha tocado asistir, una confrontación en que, gracias a la destreza dialéctica, la elegancia y la cultura de los adversarios, no había nunca un derrotado y resultaban ganando, siempre, el público y la literatura. (Vargas Llosa, 1983)

Ángel Rama, más sociólogo y hacia la izquierda; Monegal, más literario, académico y hacia la derecha, una descripción sucinta que recoge los puntos esenciales para representar a los dos intelectuales que marcaron los compases en los que se movería la crítica literaria latinoamericana; su sensibilidad a los nuevos aires políticos y estéticos condujo a la creación del canon literario latinoamericano de los sesenta ${ }^{4}$.

El antagonismo entre Rodríguez Monegal y Rama no respondía exclusivamente a las formas diversas de interpretar la literatura latinoamericana. Anterior a eso, su disputa y continua competencia fue por acaparar el espacio de la crítica en Uruguay. Como en algún momento señaló el primero: "Mi polémica con Ángel Rama no es tal, era una guerra a muerte por el poder y punto. Rama era una persona ambiciosa y yo también” (Rodríguez Monegal, en Rocca, 2006, p. 191)5 . En cierta medida, Marcha fungió para

${ }^{4}$ Respecto a la importancia de Rama y Monegal, Claudia Gilman comenta: Uno de los casos ejemplares durante el período de elaboración de las redes latinoamericanistas de los años sesenta y setenta ha sido, sin duda, el de los dos críticos uruguayos, que en muchos ámbitos se opusieron y en otras tantas cuestiones se superpusieron, en su rol de intelectuales referentes de América Latina, durante un periodo fundamental del desarrollo de nuestras letras. Efectivamente, los inventores del canon de la nueva novela latinoamericana fueron capaces de crear desde el Uruguay redes letradas antagónicas, basadas en disputas ideológicas, claro está, pero cuyo origen se remonta también a sentimientos de mutuo desagrado o competencia por legitimar su propia posición y deslegitimar la del otro" (Gilman, 2011-2012, p. 75).

${ }_{5}$ Pareciera ser que la enemistad entre ambos no residía exclusivamente en cuestiones políticas y estéticas. Sus primeras discrepancias nacen de cuestiones personales. En 1954, Monegal, desde Marcha criticó un ensayo de Carlos Rama, hermano de Ángel, publicado en el libro Problemas de la juventud uruguaya. Esto, por supuesto, no fue bien recibido por los hermanos Rama. Asimismo, desde la tribuna de Marcha, Monegal en conjunto con otros escritores, publicó el Manifiesto Los escritores nacionales a la opinión. La aparición 
los dos como el lugar propicio para ensayar las nuevas formas de hacer crítica literaria. Fue un espacio de dirección, pero también de formación del discurso crítico latinoamericano.

La enemistad entre Rama y Monegal se trasladó a otros espacios en los que igualmente se luchaba por el dominio de la palabra y las interpretaciones. En 1964, además de la polémica surgida entre ellos por la novela de Alejo Carpentier, El siglo de las luces ${ }^{6}$, Emir Rodríguez Monegal recibió la invitación para dirigir Mundo Nuevo. La "guerra a muerte" entre ellos ya no sería por ocupar el lugar central en la crítica uruguaya, sino la de Latinoamérica. A partir de aquí, la crítica se decantaría hacia dos derroteros: uno caracterizado por la idea de literatura pura, centrado en las formas y estructuras (Monegal), y otro más ideológico y social (Rama). La postura del director de Mundo Nuevo fue la de preferir un modelo inmanente de estudio literario que se apoyaba bastante bien con la noción de autonomía de la literatura, lo que propiciaba una lectura y una crítica descontextualizada y deslindada de su historia. Como señala María Eugenia Mudrovcic:

Frente a la crítica política históricamente enmarcada de Casa de las Américas, Mundo Nuevo diferencia y especifica los discursos, separando la política de la literatura, y legitimando su intervención pública en

de este texto tuvo la intención de criticar las formas de elegir los jurados para los premios nacionales y aludía a la parcialidad y posible beneficio que Carlos Rama obtenía de esto.

Las acusaciones de Monegal sobre Carlos Rama se revirtieron para 1960, cuando Ángel, ahora en la dirección de la columna cultural de Marcha, apuntó a la imparcialidad del otorgamiento del premio nacional de ensayo en la que su declarado enemigo participó con un texto derivado de una participación en radio entre él, Rama y Carlos Real de Azúa sobre la obra de Borges y Neruda. Sin embargo, la crítica de Rama ya se traslucía como algo personal, porque, si bien Monegal participó con ese texto siendo jurado del concurso, él mismo lo desestimó como posible ganador. Empero, Ángel Rama vio como algo poco político el acto de Monegal.

${ }^{6}$ Uno de los momentos ríspidos entre ellos fue en 1964, cuando los dos publicaron sus críticas sobre El siglo de las luces de Alejo Carpentier. Para Pablo de Rocca: "Si una novela de esas características era capaz de despertar una refriega entre dos intelectuales clave, era porque el destino de la Revolución cubana se vivía en un clima de tragedia, como si esta fuera, a la vez, reflejo y metonimia de todos los pueblos latinoamericanos.” (2006, p. 123). La crítica de los dos uruguayos vertidas en torno a la novela publicada en 1962 fue una lectura que tuvo a la Revolución cubana como fondo. En un momento en que se polemizaba sobre el compromiso político de los escritores y de los críticos, ésta era el punto de referencia discursivo. En ella se anclaban las discusiones estético-políticas de la época, ya fuera para criticarla, ya para apoyarla. Las reflexiones sobre la novela de Carpentier no fueron la excepción. 
nombre de la autonomía literaria. Fue su forma de controlar el referente y tratar de refundirlo en una suerte de clave interpretativa orgánica y total, ahistórica y autosuficiente (2010, p. 71).

Sin embargo, no podemos situar a Sarduy en el espacio de una crítica meramente inmanente por su filiación a Rodríguez Monegal y su revista, ya que a la par que se introducía al estructuralismo, realizaba sus relecturas de Lezama Lima para replantearse la identidad cubana y latinoamericana. El estructuralismo fue una vía para una mayor comprensión de la cultura, pero no fue un camino para despolitizar; al contrario, la importancia del estructuralismo y del postestructuralismo para el cubano radicó en la posibilidad de situar al neobarroco en la dimensión del lenguaje y convertirlo en un discurso revolucionario en la esfera de lo simbólico.

\section{La polémica con Mundo Nuevo}

En 1965 se hizo público algo que ya se sospechaba: la intervención de los Estados Unidos en la política de los países latinoamericanos. El proyecto Camelot para ese entonces ya tenía dos años de haberse puesto en marcha y no pudo ser enmascarado por más tiempo. El ejército estadounidense había estado financiando e implementado un plan estratégico dirigido a controlar los movimientos revolucionarios e insurgentes. Para ello, consideró necesario desarrollar investigaciones sociales en regiones específicas del mundo7. En un momento en que las tensiones por la Guerra Fría y la Revolución cubana, era imprescindible en la política norteamericana profundizar en

Según Louis Horowitz, el proyecto Camelot consistía en: "medir y pronosticar las causas de las revoluciones y la insurgencia en las regiones atrasadas del mundo. También se proponía buscar los medios para eliminar las causas o para bregar con revoluciones y actos de rebeldía. El Ejército de los Estados Unidos patrocinaba el Proyecto por medio de un contrato que envolvía de cuatro a seis millones de dólares, distribuido por un período de tres a cuatro años. El contrato era con la Organización de Investigaciones Científicas para Operaciones Especiales (OIES). La OIES se halla formalmente bajo la dirección de la American University de Washington, D.C., y realiza diversas investigaciones para el Ejército. Entre éstas figuran encuestas analíticas de regiones extranjeras, información de última hora sobre los asuntos militares, políticos y sociales de esas áreas, un archivo de "respuesta rápida" para la obtención inmediata de datos, cuando el Ejército así lo solicite, sobre cualquier situación militar importante” (Horowitz, 1966, p. 146). 
los procesos sociales que configuraban los grupos disidentes. La guerra se trasladó al ámbito del conocimiento social y cultural, y las sospechas por los financiamientos a instancias de investigación social y cultural por parte de EUA se incrementaron. Asimismo, fueron puestas bajo cuestionamiento instancias como el Congreso por la Libertad de la Cultura y el Instituto Latinoamericano de Relaciones Internacionales. Inmersa en este contexto nació la revista Mundo Nuevo, esta publicación "aparece como consecuencia de una coyuntura muy particular, es producto de la Guerra Fría cultural que se había instalado en el continente” (Janello, 2013, p. 116).

Para Claudia Gilman, 1966 fue un año especial para la formación del campo intelectual: "Los debates sobre la función del intelectual y la institucionalización de la comunidad intelectual latinoamericana no pueden separarse: uno y otro son interdependientes. La única separación posible es de orden metodológico." (Gilman, 2003, p. 120). Las filas se fueron cerrando para defender lo que representaba la Revolución cubana y oponerse al ataque hacia ella por parte de lo que Ángel Rama llamó "las fachadas culturales": la expresiones y proyectos que se enmascaraban como críticos, pero que eran financiados desde EUA. Uno de ellos fue la revista Mundo Nuevo. Aquí la enemistad entre Rama y Rodríguez Monegal se volvió a encender. Marcha y Casa fueron el lugar desde el cual se asestaron las críticas al proyecto del segundo.

Rodríguez Monegal había recibido la invitación para dirigir una nueva revista que sirviera como escenario para difundir la cultura latinoamericana de manera internacional. La invitación provino de Benito Milla, conocido anarquista español. El objetivo de realizar una nueva publicación ya se venía fraguando desde años anteriores, y ya había tenido un primer ensayo: la revista Temas. La historia de la fundación de Mundo Nuevo nos muestra dos puntos: el primero es que detrás de esta publicación no sólo se encontraba Rodríguez Monegal; el segundo es la intrincada red de conexiones que hubo entre distintos intelectuales para la creación de una revista con tintes "terceristas" y es aquí donde entra el Congreso por la Libertad de la Cultura en el escenario.

A través de Luis Mercier Vega, el CLC inició una etapa de renovación en Latinoamérica en la que se programó el cierre de la revista Cuadernos y la agrupación de intelectuales como Benito Milla y Aldo Solari; así como la creación del Instituto Latinoamericano de Relaciones Internacionales. 
Todo esto con el propósito de crear un espacio en el que se pudiera pensar en una ruta alternativa que no se inclinara por el capitalismo de EUA o el socialismo de la Unión Soviética.

A pesar de la insistencia de Monegal en señalar la libertad que tenía y que había exigido para aceptar el cargo de director de Mundo Nuevo, que el CLC y el ILARI estuvieran detrás de dicha publicación, no permitía que sus palabras fueran tomadas en cuenta. Como señala Gilman: "Mundo Nuevo irrumpía subrayando el andamiaje modernizador de la cultura y apoyando la retórica del diálogo y la coexistencia, denunciada por Cuba $y$ sus aliados latinoamericanos como los nuevos $y$ refinados instrumentos del capitalismo" (Gilman, 2011-2012, p. 124). Ya en circulación y habiendo sorteado los obstáculos de ser mal vista y etiquetada como un intento usurpador de EUA en Latinoamérica a través de los espacios culturales, Mundo Nuevo encaró otro escándalo: en 1966 The New York Times dio a conocer una investigación que, entre otras cosas, revelaba el financiamiento por parte de la CIA a instituciones culturales como el CLC, instancia de donde salía Mundo Nuevo. Esto prendió la polémica nuevamente, ya que se ligó inmediatamente a la revista con las políticas imperialistas de EUA. Los constantes ataques a Mundo Nuevo los resume muy bien María Eugenia Mudrovcic de esta manera:

La batería que se dirigió contra Mundo Nuevo abarcó, poco más o menos, el siguiente espectro de acusaciones: a) ser un instrumento financiado por la CIA en el marco de la política de penetración cultural iniciada por Kennedy; b) trabajar por la neutralidad de la cultura; c) camaleonizar el lenguaje de izquierda; y d) estimular una gradual despolitización del intelectual latinoamericano (2010, p. 58).

Ante estos nuevos ataques, Monegal, en el número 14 de la revista, intentó un deslinde en el que, si bien admitió el financiamiento de la CIA al CLC, insistió fuertemente en que éste no llegaba a la revista. Pero el destino de Mundo Nuevo ya estaba dado desde antes de su aparición; sin embargo, esto no socavó el ímpetu del uruguayo y su destreza para lograr colaboraciones como las de Carlos Fuentes, Gabriel García Márquez, Gabriela Mistral, Roa Bastos, Nicanor Parra, Pablo Neruda y, por supuesto, Severo Sarduy, entre otros.

La participación de estos escritores, que también colaboraron con Casa, 
nos habla de que la polarización entre Mundo Nuevo y Casa no se vio estrictamente reflejada en la dinámica de los intelectuales, y que el campo literario era mucho más complejo. Sarduy tomó en un inició partido por la Revolución cubana, como se aprecia en sus escritos antes de migrar a Europa; esta posición la matizó con el tiempo, sin llegar a contraponerse abiertamente. En todo caso el acontecimiento revolucionario le sirvió como catalizador para reflexionar la identidad cubana y latinoamericana. Después de la Revolución no se podía seguir pensando en lo cubano desde las mismas claves, se volvía necesario repensar las problemáticas con otras palabras, con otros conceptos que permitieran escudriñar de diversa manera la situación. El regreso a Lezama Lima se volvió inminente, pero no fue el mismo Lezama, sino el Lezama de Sarduy.

\section{Mundo Nuevo y el Neobarroco en ciernes}

En la articulación del campo intelectual de los años sesenta, el neobarroco vino a agregar nuevas tesituras y a descubrir otras dimensiones de lo político-cultural. El neobarroco vino a refrescar, con una nueva propuesta, una discusión que se venía anquilosando y reduciéndose a esencialismos. Severo Sarduy, desde la palestra que le ofreció Mundo Nuevo, empezó a conjuntar dos aspectos que parecían irreconciliables para ese entonces: la unión de una propuesta estructuralista-formal y la visión cultural-ideológica para leer la literatura. Cada una representada por los dos epígonos de la crítica literaria latinoamericana: Ángel Rama y Emir Rodríguez Monegal. Para Severo Sarduy, este último fue uno de sus maestros: "Emir estuvo muy ligado no sólo a mi escritura - que, en parte, le debo-, sino una motivación más profunda, a su justificación y a su sentido", poco más adelante en el mismo texto recuerda el vínculo entre los dos durante: "los largos años de Mundo Nuevo, y en los de la complicidad que siguió esa polémica aventura" (1999, p. 93). Aunque su amistad y colaboración directa con el uruguayo ha contribuido a la idea de que la obra sarduyana tendió más a lo formal, el cubano logró darle un giro social, cultural y político a su obra.

En el ámbito de la crítica literaria, Sarduy apostó por una forma arriesgada de lectura. Como señala Valentín Díaz: "el neobarroco es una máquina lectora" (2011, p. 52), que en sus mecanismos contiene diferentes 
claves para reinterpretar textos y generarlos. Siguiendo con la metáfora, los engranajes del neobarroco se fueron concatenando en la revista Mundo Nuevo que, si bien ya tenía su propia sintaxis, fue excedida por éste.

John Beverly, al hablar sobre el barroco, atina a un punto que Sarduy parecía tener muy en cuenta y es que: "se trata evidentemente no sólo de una evaluación de la naturaleza exacta del barroco en su contexto histórico, sino también de su actualización como una ideología de lo estético (y sobre todo de lo literario) en el presente cultural latinoamericano" (Beverly, 1988, p. 217). La forma en el neobarroco es el contenido, es la suma ideológica y política de su contemporaneidad. La propuesta sarduyana es una reactualización del barroco en el contexto postrevolucionario, en el que la agenda de discusión sobre el latinoamericanismo cobró nueva fuerza. Aquí es necesario un análisis de algunos de los textos publicados en la revista dirigida por Rodríguez Monegal para ir perfilando una pequeña genealogía del neobarroco.

En la vida efímera de Mundo Nuevo (de 1966 a 1968), Sarduy publicó 11 artículos y estuvo presente en un texto derivado del diálogo entre él, Rodríguez Monegal y Tomás Segovia en torno a Rubén Darío. Gran parte de los textos fueron reunidos y publicados posteriormente en Escritos sobre un cuerpo (1968) por la editorial Sudamericana. La extracción de estos textos de la revista para ser publicados como libro es quizá lo que ha propiciado el olvido de la importancia que tuvo Mundo Nuevo en la configuración del neobarroco y, por tanto, la generalizada lectura descontextualizada de la obra del autor de Cobra.

En 1966, en su primer artículo de Mundo Nuevo titulado "Sobre Góngora: la metáfora al cuadrado", el escritor cubano comenzó a dar las primeras notas, y a echar lo primeros cimientos sobre los que se erigió el neobarroco. Aquí, Sarduy hace una lectura que pretende combinar el estructuralismo de Roland Barthes y el psicoanálisis de Lacan para hablar del poeta cordobés, a partir de tres aspectos: la metáfora, la cultura y el sentido. Con la primera de ellas se empeña en mostrar que la poesía, la barroca especialmente, es un distanciamiento con la naturaleza. Todo es llevado al plano del lenguaje; sin embargo, hace una distinción: existe un lenguaje puro, que es aquel que no contiene residuos metafóricos o retóricos, un lenguaje estrictamente referencial y denotativo; y existe otro, el barroco, en el que todo es impureza. La metáfora, entonces, es signo de una contaminación, 
de una transgresión de lo puro y natural. La metáfora es una depravación del lenguaje. Mina la pureza denotativa, la enferma al romper la unión entre el significado y el significante.

La transgresión de la metáfora consiste en que ésta, al convertirse en el doble del mundo, lo repliega y asedia, dejando ver que: "La realidad -el paisaje- no es más que eso: discurso, cadena significativa y por lo tanto descifrable" (Sarduy, 1966, p. 84). El lenguaje poético es una suerte de procedimiento en el que todo se textualiza, todo se vuelve signo. La metáfora es el síntoma del barroco: enfermedad del lenguaje que se verifica en un exceso. Pero esta distancia que se sortea entre el significado y el significante en el barroco no es como en la poesía pura de Mallarmé, sino como en la de Rubén Darío. A pesar de que en los dos la palabra funge como "doble absoluto del universo", en el francés se da como una ausencia de éste, mientras que en el nicaragüense como "proliferación incesante, como horror del vacío" (Sarduy, 1967, p. 36).

Si todo se cae en las redes de la textualidad, el cuerpo no es, por supuesto, la excepción. Cuando el signo se acumula en el cuerpo, se erotiza. Por ello Sarduy, al hablar de Darío señala: "Pero si Darío lee el mundo como un texto, hace invertir su propio cuerpo en ese texto, y entonces, como tenemos en la lectura lo somático, tenemos también lo erótico. Y aquí yo creo que tocaríamos una noción capital en Darío: la Retórica es una Erótica” (1967, p. 42). La secuencia del barroco va de la metáfora como enfermedad del lenguaje, pasa por la textualización del mundo y del cuerpo para llegar a la erótica del lenguaje. Toda retórica es una erótica, dice el cubano. Todo lenguaje es erótico en tanto que es trasgresión de la naturaleza, y con esto también se revela la presencia de George Bataille en el neobarroco. El exceso barroco es la pulsión erótica del lenguaje por alcanzar el goce.

Antes de seguir con el erotismo barroco del lenguaje y trasgresión, es preciso señalar que la contraposición entre naturaleza y lenguaje, además de observarla en Góngora, Sarduy también la ve en su maestro Lezama. En las dos poéticas barrocas, el verismo del leguaje queda excluido. La estructura lingüística es la que lee la naturaleza para crear un doble de ella. Pero ese doble no viene como un derivado de un original. La duplicación del mundo se da con la finalidad de parodiarlo, no para tomarlo como su fundamento y origen. 
Y es que en Lezama el apoderamiento de la realidad, la voraz captación de la imagen opera por duplicación, por espejeo. Doble virtual que irá asediando, sitiando al original, minándolo de su imitación, de su parodia, hasta suplantarlo. [...]

La demarche lezamesca es, pues, metafórica. Pero la metáfora, el doble devorador de la realidad, desplazador del origen, es siempre y exclusivamente de naturaleza cultural. Como en Góngora, aquí es la cultura quien lee la naturaleza - la realidad-y no a la inversa [...] Lo lingüístico arma con sus materiales un andamiaje, una geometría refleja que define y reemplaza lo no lingüístico. (Sarduy, 1968, p. 5)

La metáfora es lo cultural. La metáfora devoradora desplaza, suple a la realidad parodiándola. Cuando señala esto, es inevitable recordar cómo en El Cristo de la rue Jacob (1987), Sarduy analiza una carta que había recibido de Lezama Lima en 1969, donde éste declina su invitación para ir a París con el pretexto de la publicación de Paradiso por Éditions du Seuil. El texto de Sarduy es un examen de esta misiva lezamiana, producto de una lectura, porque el neobarroco, antes de ser escritura es un acto de codigofagia; y en él las palabras de Lezama Lima van siendo devoradas, subsumidas por los pliegues de la escritura neobarroca que se vuelve una escritura que en su voracidad también ofrece una hospitalidad sin condición, en el sentido de Derrida, que asimila al otro en sí, pero sin subordinación o jerarquía.

Tanto en Góngora como en Darío y Lezama, la trasgresión metafórica es de ese orden. Aquí inicia la separación con el barroco carpentieriano y dorsiano, que sitúan lo barroco en la naturaleza. El barroco lezamesco y sarduyano se ubica en el espacio simbólico-cultural y se caracteriza por su cariz trasgresor y perverso: erótico.

La lectura apasionada que hizo del autor de Paradiso llevó a Sarduy a reclamarse como uno de sus herederos; quizá el mejor de ellos, puesto que realizó una labor hermenéutica que trajo algo nuevo a la obra lezamiana a la vez que se apropiaba de ella. Hizo para sí el saber barroco. Como escribió Sarduy:

Heredero es el que descifra, el que lee. La herencia más que una donación, es una obligación de hermenéutica. Heredero es el que, gracias a la fulguración de un desciframiento, se apodera instantáneamente de un saber [...] El heredero, pues, al descifrar, funda. La interpretación es 
cimiento. Heredar a Lezama es practicar esa escucha inédita, única, que escapa a la glosa y a la imitación. (1999, p. 1411)

En este sentido, La Expresión Americana (1957) puede ser tomada como la base de esa hermenéutica y esa escucha practicada por Sarduy y con la cual comenzó a urdir su concepción de lo barroco. Los ensayos de Lezama Lima y en general su obra le ofrecieron las herramientas para configurarlo como expresión y característica de la cultura latinoamericana, pero no en el sentido esencialista que le daba Carpentier a esto.

La metáfora se entrelaza con otras creando una superposición: la de las culturas que Sarduy ve en Cuba. Para él, la identidad cubana no es una síntesis de culturas, sino su superposición, "forma elemental del diálogo" (1999, p. 1396), tal como lo ve en Paradiso y como intentó reproducir en De donde son los cantantes (1967). La metáfora es el elemento idóneo para hablar de la identidad del sujeto, puesto que éste es lenguaje, cultura.

Cuba no es una síntesis, una cultura sincrética, sino una superposición. Una novela cubana debe hacer explícitos todos los estratos, mostrar todos los planos "arqueológicos" de la superposición [...] Lo cubano aparece así, en la violencia de ese encuentro de superficies, como adición y sorpresa de lo heterogéneo yuxtapuesto. (Sarduy, 1968, p. 9)

Lo que pareciera a ojos poco agudos mera retórica vacía, es en realidad el inicio del programa neobarroco, el establecimiento de sus presupuestos y de la actualización ideológica de lo estético que señala Beverly. De este modo, Sarduy parte de lo siguiente: para hablar de la identidad del sujeto cubano o latinoamericano es necesario llevar la problemática al lenguaje, a una textualización generalizada que termine por pervertir la realidad y enfermarla de metáfora, y ver que la identidad es una superposición de huellas que necesitan de un estudio arqueológico, en el sentido de Foucault, para ser comprendidas.

La acción política del neobarroco se organiza en torno a la trasgresión: primero, del lenguaje puro, referencial y denotativo de la racionalidad y segundo, de la realidad al duplicarla. ¿No hay aquí una implicación revolucionaria que niega la realidad material para construir una de mera virtualidad travestida? El nacimiento del neobarroco surge como un asedio al fetichismo que la racionalidad moderna tiene por la materialidad. El ba- 
rroco se torna furioso, perverso, trasgresor, niega la realidad y se vuelca a configurar otra. El neobarroco es una revolución erótica al nivel del signo. Como señala Sarduy en Mundo Nuevo sobre Sade:

La blasfemia como acto erótico consagra cada jornada a la burla del poder invisible (Dios) para permitir la caída del poder visible (el Rey); reivindica cada acto en nombre del ateísmo y la revolución.

Pero la blasfemia no es lo único que se repite. La repetición (también en el sentido que en francés tiene esta palabra: ensayo de una obra) es el soporte último de la imaginación sádica y, sin duda, el de toda perversión. (1968, p. 5)

El desplazamiento metonímico del neobarroco se hilvana así: metáfora, trasgresión, perversión, duplicación, blasfemia, sadismo, erotismo: revolución como repetición del pensamiento, del lenguaje y la realidad, matizada por Sarduy de la siguiente manera:

(No hablo de la trasgresión pueril que es el arte "de denuncia": el pensamiento burgués, no sólo no se molesta, sino que se satisface ante la representación de la burguesía como explotación, del capitalismo como podredumbre.) Lo único que la burguesía no soporta, lo que la "saca de quicio" es la idea de que el pensamiento puede pensar sobre el pensamiento, de que el lenguaje pueda hablar del lenguaje, de que un escritor no escriba sobre algo, sino que escriba algo. $(1967$, p. 8$)$

Con esto, ¿̇se puede seguir pensando que la obra de Sarduy es una expresión hedonista-formal, preocupada exclusivamente por las estructuras sígnicas? Por supuesto que no. El neobarroco se instala en la discusión político-revolucionaria latinoamericana como una propuesta trasgresora confrontada a cualquier realismo, incluido el mágico, a cualquier verismo del lenguaje burgués y capitalista.

La repetición, la iteración, como ensayo de una obra, es decir, como teatralidad, es el lugar propicio para las transformaciones y las inversiones. Sólo en el espacio de la representación: el lugar sin límites, como la novela de José Donoso, se puede gestar la trasgresión. Pero no en el seguimiento de la cadena significante como ley, sino en su resquebrajamiento derivado del acontecimiento de la perversión. El travestismo es el ejemplo de esa posibilidad, puesto que ya no apela a la exterioridad del signo, es decir, 
detrás de la máscara del travestismo no hay nada más: no hay origen. El travestismo es el ejemplo máximo de la metáfora devoradora de la realidad. Como Sarduy señala respecto a la exterioridad del texto:

Ese prejuicio, manifiesto o no, edulcorado con distintos vocabularios, asumido por sucesivas dialécticas, es el del realismo. Todo en él, en su vasta gramática, sostenida por la cultura, garantía de su ideología, supone una realidad exterior al texto, a la literalidad de la escritura. Esa realidad, que el autor se limita a expresar, a traducir, dirigiría los movimientos de la página, su cuerpo, sus lenguajes, la materialidad de la escritura. Los más ingenuos suponen que es la del "mundo que nos rodea", la de los eventos; los más astutos desplazan la falacia para proponernos una entidad imaginaria, algo ficticio, un "mundo fantástico". Pero es lo mismo: realistas puros - socialistas o no- y realistas "mágicos" promulgan y se remiten al mismo mito. Mito enraizado en el saber aristotélico, logocéntrico, en el saber de origen, de un algo primitivo y verdadero (1968, p. 68).

El mito logocéntrico de la referencialidad textual se ancla en la ideología burguesa. Incluso el realismo mágico, esa propuesta de expresión latinoamericana, se circunscribe aún en la metafísica de la exterioridad del texto, en la falacia de la verdad como concordancia entre signo y realidad propuesta por la modernidad racional. En este sentido, el neobarroco inicia como ataque severo y radical en el plano de lo simbólico, descubriendo las grietas de las expresiones poéticas disidentes en Latinoamérica.

Mundo Nuevo fue la matriz de gestación del neobarroco. La crítica literaria sobre Góngora, Darío, Lezama, Sade, Fuentes, Cortázar, Elizondo, Donoso, entre otros, vertida en los diferentes artículos publicados en esta revista, se manifestó como una máquina lectora (Díaz, 2011). La crítica como un proceso de lectura y repetición en la escritura, devuelve los textos de los escritores con algo nuevo: una marca ideológica que no contenían. Ese discurso ideológico en la crítica de Sarduy está presente como una dispersión de elementos que corren al paralelo de ella. Es una anamorfosis que hay que mirar de lado para reconocerla. En respuesta sintomática al momento socio-cultural que enfrentaba Latinoamérica con el proyecto Cámelot, con la intromisión de EUA en las políticas de los países latinoamericanos y con las respuestas anticapitalistas e imperialistas de algunos intelectuales, Sarduy arroja el embrión del neobarroco en Mundo Nuevo, 
participando de las polémicas en el campo intelectual latinoamericano, en el replanteamiento y reflexión de la identidad cubana y latinoamericana en el marco posrevolucionario. El neobarroco se gestó en las páginas de Mundo Nuevo como una propuesta a las problemáticas de Latinoamérica, pero pensadas desde un ángulo diferente en el que el lenguaje tuvo un lugar predominante, y donde la crítica a aspectos puntuales de la modernidad empezó a mostrarse.

\section{Referencias}

Beberly, J. (1988). Nuevas vacilaciones sobre el barroco. Revista de Crítica Literaria Latinoamericana (No. 28), pp. 215-227.

Díaz, V. (2011). Apostillas. En S. Sarduy, El barroco y el neobarroco. Buenos Aires: El Cuenco de Plata.

Gilman, C. (2003). Entre la pluma y el fusil. Debates y dilemas del escritor revolucionario en América Latina. Buenos Aires: Siglo veintiuno editores Argentina S.A.

Gilman, C. (2011-2012). Enredos y desenredos de Ángel Rama y Emir Rodríguez Monegal. Nuevo texto crítico, Vol. 24-25 (No. 47-48), pp. 6992.

Horowitz, L. (1966). Vida y muerte del proyecto Camelot. Revista de Ciencias Sociales y Humanidades, Vol. 10 (No. 2), pp. 145-165.

Jannello, K. (2013). El boom latinoamericano y la Guerra Fría cultural. Nuevas aportaciones a la gestación de la revista Mundo Nuevo. IPOTESI, Vol. 17 (No. 2), pp. 115-133.

Mudrovcic, M. E. (2010). Nombres en litigio. Las guerras culturales en América Latina: del happening desarrollista a la posguerra fría. Rosario: Beatriz Viterbo.

Rocca, P. (2006). Ángel Rama y Emir Ródriguez Monegal y el Brasil. Dos caras de un proyecto latinoamericano. Universidad de Sao Paulo: Tesis de doctorado.

Sánchez Prado, I. (Ed.). (2006). América Latina: giro óptico. Puebla: Universidad de las Américas Puebla.

Sarduy, S. (1966). Sobre Góngora: la metáfora al cuadrado. Mundo Nuevo (No. 6), pp. 84-86. 
Sarduy, S. (1967). Del Ying al Yang. Mundo Nuevo (No. 13), pp. 4-13.

Sarduy, S. (1968). Dispersión/ falasas notas. Homenaje a Lezama Lima. Mundo Nuevo, 5-17.

Sarduy, S. (1999). Obra Completa . Madrid; Barcelona; Lisboa: UNESCO. Sarduy, Severo, Monegal, Emir, Segovia, Tomás. (1967). Nuestro Rubén Darío. Mundo Nuevo (No. 7), pp. 33-46.

Sarlo, B. (1992). Intelectuales y revistas: razones de una práctica. América: Cahiers du CRICCAL (No. 9-10), pp. 9-16.

Vargas Llosa, M. (diciembre de 1983). Ángel Rama: la pasión y la crítica. El comercio de Lima. 